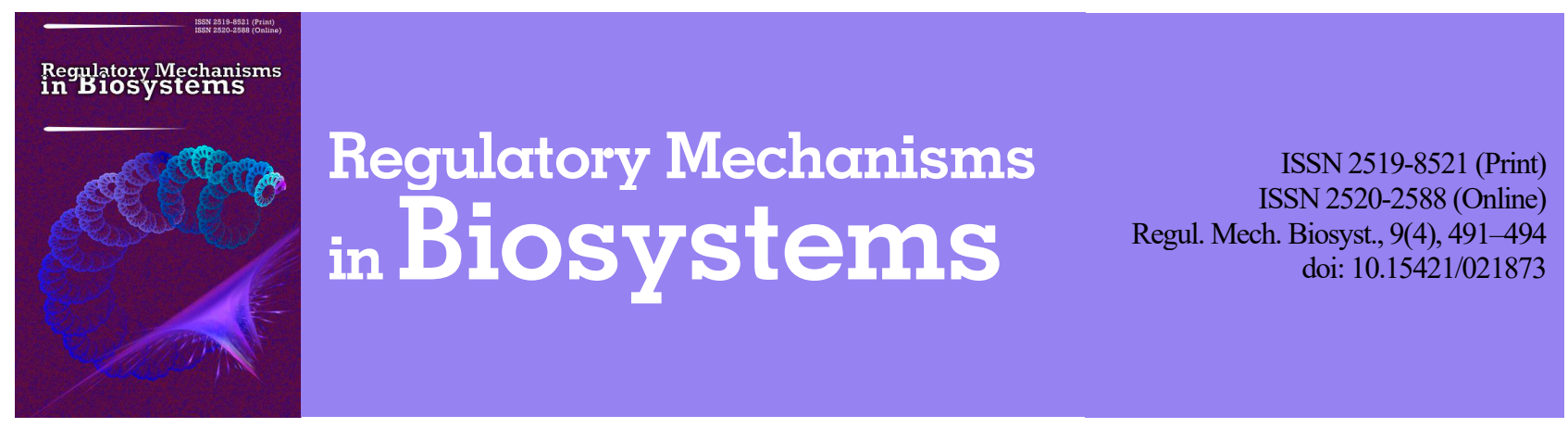

\title{
Compositions of essential oils with antimicrobial properties against isolates from oral cavities of patients with inflammatory diseases of the periodontium
}

\author{
M. V. Kryvtsova*, Y. Y. Kostenko*, I. Salamon** \\ *Uzhhorod National University, Uzhhorod, Ukraine \\ **University of Prešov, Prešov, Slovakia
}

Article info

Received 28.09.2018

Received in revised form

20.10.2018

Accepted 21.10.2018

Uzhhorod

National University,

Pidhirna st., 46,

Uzhhorod, 88000 ,

Ukraine.

Tel.:+ 38-050-278-54-97.

E-mail: maryna.krivcova

@gmail.com

University of Prešov

17 Novembra, 1 ,

Prešov, 08116, Slovakia.

Kryvtsova, M. V., Kostenko, Y. Y., \& Salamon, I. (2018). Compositions of essential oils with antimicrobial properties against isolates from oral cavities of patients with inflammatory diseases of the periodontium. Regulatory Mechanisms in Biosystems, 9(4), $491-494$. doi:10.15421/021873

The significant spread of antibiotic-resistant microorganisms which are part of microbial associations of the oral cavity is considered one of the main causes for the complications and relapses of inflammatory diseases of the periodontium. This problem underlines the importance of constant monitoring of the circulation of polyantibiotic-resistant isolates, and development of new approaches and means of correction for the microbiocoenosis of the oral cavity affected by inflammatory processes. The paper is dedicated to research of antimicrobial properties of essential oil compositions against opportunistic pathogenic microorganisms, agents of inflammatory diseases of the periodontium. Out of the microorganisms isolated from the nidus of inflammation, the extra antibiotic-resistant ones were chosen. For the purpose of antibiotic susceptibility and antimicrobial activity testing, the disc diffusion method was used. The following compositions were manufactured from essential oils: Hyssopus officinalis L. + Rossmarinus officinalis L.; Menta piperita L. + H. officinalis; R. officinalis + Coriandrum sativum L.; R. officinalis $+M$. piperita $+H$. officinalis. The compositions $H$. officinalis $+R$. officinalis; $M$. piperita $+H$. officinalis were shown to have the highest level of antibacterial activity against clinical and typical isolates. Combinations of essential oils demonstrated a broader spectrum of activity against microorganisms than their components taken separately. Certain essential oils and the compositions $H$. officinalis + R. officinalis; $M$. piperita $+H$. officinalis were ascertained to have a high anti-mycotic activity against Candida genus microscopic fungi. This fact proves the advantage of application of combinations of essential oils compared to the use of their separate components. However, not all variants reviewed showed additive antimicrobial effect of the use of combinations of essential oils. The compositions that showed high antibacterial properties against the reviewed isolates may be used for oral hygiene products.

Keywords: antibiotic resistant isolates; opportunistic pathogenic microorganisms; antibacterial activity; anti-mycotic effect

\section{Introduction}

The continuously growing trend for formation and circulation of antibiotic-resistant strains of opportunistic pathogenic microorganisms gives relevance to research on alternative means of treatment with antimicrobial properties. It is the representatives of the facultative microbiota of the oral cavity that take up dominating positions in the structure of the inflammatory periodontium. Bacteria of the Streptococcus, Staphylococcus, Enterococcus, Esherichia, Klebsiella, Pseudomonas genera and microscopic fungi of the Candida genus serve as an etiological factor of the inflammatory processes characterized by lingering persistence and resistance to antibacterial materials (Schindel, 2013; Jakobi et al., 2015). Colonization of the mucous membrane by opportunistic pathogenic microorganisms is affected by a number of factors. For example, changes were shown to occur in the composition of microcoenosis and in adhesive properties of the bacteria in the zone of peri-implant sites (Größner-Schreiber et al., 2008). Under such conditions, constant monitoring of circulating polyresistant strains of opportunistic pathogenic bacteria and elaboration of new approaches to antibacterial therapy acquires specific significance (Tada et al., 2006). Development and introduction of new antibacterial materials and approaches to treatment and correction of inflammatory processes caused by opportunistic pathogenic microorganisms, and search for the antibacterial materials that may in a number of cases become an alternative to antibiotic treatment, also remains today an issue of primary importance. A number of recent developments have noted antimicrobial and anti-inflammatory properties of pilot plant-based materials, extracts and essential oils against isolates from the oral cavity (Assaf et al., 2016). The authors noted the ability of essential oils to affect the biofilm-producing properties of microorganisms. The study shows (Kalemba \& Kunicka, 2003; Bueno et al., 2017) the effect of essential oils upon biofilms.

Possessing a certain spectrum of antimicrobial activity, plant-based materials may less often cause complications and disorders in biocoenoses. Essential oils with a high level of antimicrobial activity (Rhos \& Recio, 2005; Murbach Teles Andrade et al., 2013), high antioxidant (Millezi et al., 2012) and anti-inflammatory properties are widely used in medicine, cosmetology and the food industry, and they are worth peculiar attention in this respect (Newman \& Cragg, 2007; Bueno et al., 2017). At the same time, however, the effect of essential oils is often characterized by a narrow-spectrum antimicrobial activity. In this respect, it seems vital to be able to develop compositions with precisely determined antimicrobial properties, for such compositions may be used as an active basis for toothpastes, rinsers, gels and ointments used for prevention and correction of inflammatory diseases of the oral cavity, and for inhibition of levels of opportunistic pathogenic microbiota.

The purpose of this paper was to study the antimicrobial activity of essential oils compositioni upon antibiotic-resistant clinical isolates from the patients' oral cavities, associated with general periodontitis.

\section{Material and methods}

Isolation of microorganisms. As test culture, the following bacteria and yeast from the American Type Culture Collection were used: Can- 
dida albicans ATCC 885-653, Staphylococcus aureus ATCC 25923, Escherichia coli ATCC 25922, Enterococcus faecalis ATCC 29212, Streptococcus pyogenes ATCC 19615 and Pseudomonas aeruginosa ATCC 27853. We also used clinical strains of bacteria and yeasts (S. aureus, E. coli, S. pyogenes, S. pneumoniae, C. albicans, C. krusei, C. tropicalis isolated from the oral cavities of patients suffering from inflammatory periodontium. We chose the clinical strains with multiple resistance to antibiotics. The isolates that caused periodontium inflammatory processes were isolated on the basis of the Dental Polyclinic, Uzhhorod National University; the antimicrobial activity of the essential oils (EOs) and disinfectants was studied at the Microbiological Laboratory of the Department of Genetics, Plant Physiology and Microbiology, Uzhhorod National University.

Biological material samples from the mucous membrane of the nidus of the inflammatory process were taken using a sterile transport system (a test-tube with a gel and applicator for biological liquids, made by FLmedical, Italy). The material was plated on the following nutrient media: Sabouraund Dextrose Agar, and HiCrome ${ }^{\mathrm{TM}}$ Candida Differential Agar (Himedia) for cultivation of microscopic fungi; blood agar for hemolytic microflora, in particular Streptococcus and Neisseria genera microorganisms; Endo and Ploskorev agar (Farmaktiv, Ukraine) for Enterobacteriaceae; Mannitol Salt Agar (Biolif-Italia) for Staphylococcus genus bacteria, Bile esculin agar (Biolif-Italia) for Enterococci. The pure culture of microorganisms was obtained by sector inoculation according to Gold. The bacteria and yeasts were identified using macromorphological, micromorphological, physiological and biochemical tests with the use of Entero-test, Strepto-test, and Staphylo-test, made by Erba Lachema.

Antibiotic susceptibility testing. The antibiotic sensitivity of bacteria and microscopic fungi was identified by the disc diffusion method according to (Order No. 167 of the Ministry of Public Health of Ukraine of 05/04/2007; EUCAST (European Committee on Antimicrobial Susceptibility Testing). Inoculum of isolates was prepared from 24 hour old culture grown on Sabouraund Dextrose Agar (Himedia) for Candida and Muller-Hinton agar (Himedia) for bacteria isolates. Colonies were suspended in $5 \mathrm{ml}$ of sterile $0.85 \%$ Saline. Inocula of isolates $100 \mu \mathrm{L}$ in physiological solution were adjusted to the equivalent of $0.5 \mathrm{McF}$ arland standards and spread on the surface of agar.

Sterile filter paper disks were placed on the plate previously inoculated with a microbial suspension and incubated at $35 \pm 2{ }^{\circ} \mathrm{C}$ ( 48 hours) for yeasts and at $37 \pm 2{ }^{\circ} \mathrm{C}$ ( 24 hours) for bacteria. Size of inhibition zone diameters surrounding filter paper disc was measured and compared to the Zone Diameter Interpretive Standards.

The bacteria isolates were screened for susceptibility to a panel of three groups of antibiotics: ampicillin $(10 \mu \mathrm{g})$, amoxicillin-clavulanic acid $(20 / 10 \mu \mathrm{g})$, cefazolin $(30 \mu \mathrm{g})$, ceftriaxone $(30 \mu \mathrm{g})$, imipenem $(10 \mu \mathrm{g})$, meropenem $(10 \mu \mathrm{g})$, cefuroxime $(50 \mu \mathrm{g})$, cefoperazone $(75 \mu \mathrm{g})$, ciprofloxacin $(5 \mu \mathrm{g})$, levofloxacin $(5 \mu \mathrm{g})$, gatifloxacin $(5 \mu \mathrm{g})$, norfloxacin $(10 \mu \mathrm{g})$, ofloxacin $(1 \mu \mathrm{g})$, lomefloxacin $(10 \mu \mathrm{g})$, tetracycline $(30 \mu \mathrm{g})$, erytromy$\operatorname{cin}(15 \mu \mathrm{g})$, azitromycin $(15 \mu \mathrm{g})$, clarithromycin $(15 \mu \mathrm{g})$. The yeasts isolates were screened for susceptibility to the following antibiotics: $(6 \mathrm{~mm}$ in diameter) with nystatin $(50 \mu \mathrm{g})$, itroconazole $(10 \mu \mathrm{g})$, fluconazole $(25 \mu \mathrm{g})$, ketoconazole $(10 \mu \mathrm{g})$, voriconazole $(1 \mu \mathrm{g})$, klotrimazole $(10 \mu \mathrm{g})$, miconazole $(50 \mu \mathrm{g})$.

The sensitivity of microorganisms to EOs was determined by the standard disk diffusion test (Balouiri et al., 2016). Sterile filter paper disks ( $6 \mathrm{~mm}$ in diameter) impregnated with $10 \mu \mathrm{L}$ of essential oil were placed on the dish plate previously inoculated with a microbial suspension. Bacterium inocula $100 \mu \mathrm{L}$ in physiological solution were adjusted to the equivalent of 0.5 McFarland standard, and evenly spread on MullerHinton agar surface (incubated at $37 \pm 2{ }^{\circ} \mathrm{C}$ for 24 hours), yeasts - on SDA agar (incubated at $35 \pm 2{ }^{\circ} \mathrm{C}$ for 48 hours). The diameters of the inhibition zones were measured in millimeters including diameter of disc. Each antimicrobial assay was performed at least three times.

Isolation of the essential oil. The essential oils of the following plants were used: Rossmarinus officinalis L., Menta piperita L., Hyssopus officinalis L., Coriandrum sativum L. (produced by "Calendula", Nova Lubovna, Slovakia). Each sample of the plant parts with weight of $10 \mathrm{~g}$ was ground in a blender. The essential oil from this raw-material were prepared by hydro-distillation ( $2 \mathrm{hrs})$ in a Clevenger-type apparatus according to the European Pharmacopoeia and a mixture of hexane and diethyl ether $(1: 1)$ was used as a collecting solvent. The essential oils stored under $\mathrm{N}_{2}$ at $+4{ }^{\circ} \mathrm{C}$ in a dark space before their composition identification

Chemical composition of EOs were as follows:

- rosmary essential oil (Rossmarinus officinalis L.): $\alpha$-pinene $19 \pm$ $1 \%$, camphene $9 \pm 1 \%$, $\beta$-pinene $5 \pm 1 \%$, cineole $25 \pm 1 \%$, p-cymene $17 \pm 1 \%$, camphor $19 \pm 1 \%$, bornylacetate $<2 \%, \alpha$-terpineole $2.5 \pm$ $0.2 \%$, borneole $2.0 \pm 0.2 \%$.

- peppermint essential oil (Mentha piperita L.): limonene $2.5 \pm$ $0.2 \%$, cineole $5.2 \pm 0.2 \%$, menthone $24 \pm 1 \%$, menthofuran $3.2 \pm 0.2 \%$, isomentone $3.8 \pm 0.2 \%$, menthyl acetate $4.1 \pm 0.2 \%$, isopulegol less than $0.1 \%$, menthol $39 \pm 1 \%$, pulegone $1.1 \pm 0.1 \%$, carvone $0.3 \pm 0.1 \%$, cineole $2.1 \pm 0.1 \%$.

- hyssop essential oil (Hyssopus officinalis L.): $\alpha$-pinene $15 \pm 1 \%$, pinocampfene $35 \pm 2 \%$, isopinocampfene $20 \pm 1 \%$.

- coriander oil (Coriandri sativum L.): linalool $53.0 \pm 2 \%$.

Statistical analysis. Data obtained were expressed as mean \pm standard deviation (SD) of three measurements. The Tukey test was applied for comparisons of means, differences were considered significant at $\mathrm{P}<0.05$.

\section{Results}

The following compositions were manufactured in $1: 1$ ratio from essential oils based on the results of the previous studies of antimicrobial activity:

1) H. officinalis + R. officinalis;

2) M. piperita + H. officinalis;

3) R. officinalis + C. sativum;

4) R. officinalis + M. piperita + H. officinalis.

Composition No. 1 had a significant antibacterial effect against S. aureus, especially against its clinical strains; it also showed moderate (however, the highest one among all combinations reviewed) activity against S. pneumoniae (Table 1). Composition No. 1 was ascertained to have high antibacterial activity against clinical strains of $E$. coli and E. faecalis; in this case, its antibacterial effect was statistically reliably higher than that of its components if taken separately. An additive effect of activity of essential oils in the composition M. piperita $+H$. officinalis was recorded on clinical isolates of $C$. albicans and C. tropicalis (Table 2).

Composition No. 2 had a pronounced antimicrobial effect against the isolates taken into the experiment. It also showed antibacterial activity against typical and clinical strains of $S$. aureus. At the same time, the effects against clinical strains of staphylococcus practically did not differ for $H$. officinalis and its combination with mint essential oil. The highest antibacterial effect of this composition was recorded against $S$. pyogenes. The most pronounced antimycotic effect of Composition No. 2 was shown against $C a n d i d a$ genus microscopic fungi.

Composition No. 3 revealed moderate and weak antibacterial effect, if compared with Compositions No. 1 and 2. C. sativum was ascertained to have high antibacterial effect against typical strains of $E$. coli, however it showed no effect against its clinical strains whatsoever. The antimicrobial properties of Composition No. 3 were lower than those of its components if taken separately.

Composition No. 4 had high antimicrobial activity against $E$. faecalis and $E$. coli. The compositions were ascertained to have more pronounced antimycotic activity against typical and clinical isolates of $C$. albicans, C. tropicalis, and C. krusei, i.e. combinations of essential oils showed a higher and broader spectrum of antimycotic activity than their components taken separately. Composition No. 2 showed somewhat higher effect than Composition No. 1. Composition No. 4 had a high effect against the clinical isolate of C. albicans.

\section{Discussion}

Determination of antimicrobial activity of medicinal plants, their separate components and products, such as extracts, essential oils, etc., against microorganisms isolated from the nidus of the inflammatory process with a high level of antibiotic resistance, is a matter of peculiar interest from the viewpoint of searching for medicines alternative to antibiotics and disinfectants (Koba et al., 2011). At the same time, natural 
plant components with antimicrobial, aromatic and antioxidant properties do not destroy the microbiocoenosis of the human organism and less often cause adverse side-effects. The antimicrobial properties of essential oils often depend upon the plant materials, plant chemotype, and natural and climatic conditions of their growth.

A considerable amount of scientific research has been dedicated to the selection of plants as a source of essential oils with a high level of this or that active substance. The results presented by Mohamed et al. (2010) showed the antibacterial activity of essential oils from four Lamiaceae aromatic plants (Thymus capitatus L., Lavandula dentata L., Salvia officinalis L. and Mentha rotundifolia L.), used in traditional folk medicine of Algeria. The work described the activity of essential oils against three resistant bacterial strains (Staphylococcus aureus, Klebsiella pneumoniae and Pseudomonas aeruginosa) isolated from hospitalized patients, and standard strains of the same bacteria. The authors noted that the highest antibacterial potentiality was demonstrated by the essential oil from T. capitatus leaves, followed by that of S. officinalis. Marino et al. (1999) determined the high antibacterial effect of essential oils of Thymus vulgaris $\mathrm{L}$. against common bacteria (Pseudomonas aeruginosa, Klebsiella pneumoniae, Enterococcus faecalis, Salmonella typhimurium, Escherichia coli and Staphylococcus aureus). Our previous studies showed high antimycotic activity of essential oils against Candida genus microscopic fungi (Kryvtsova et al., 2017, 2018; Salamon et al., 2017). The antimicrobial effect of essential oils against oral cavity pathogens was shown in (Koba et al., 2011).

Table 1

Antibacterial activity of essential oils and their compositions against typical and clinical isolates of opportunistic infectious agents $(\mathrm{mm}, \mathrm{x} \pm \mathrm{SD}, \mathrm{n}=3$ )

\begin{tabular}{|c|c|c|c|c|c|c|c|}
\hline Essential oils & $\begin{array}{l}\text { Staphylococcus } \\
\text { aureus } \\
\text { ATCC } 25923\end{array}$ & $\begin{array}{l}\text { Staphylococcus } \\
\text { aureus (clinic) }\end{array}$ & $\begin{array}{l}\text { Enterococcus } \\
\text { faecalis } \\
\text { ATCC } 29212\end{array}$ & $\begin{array}{l}\text { Streptococcus } \\
\text { pyogenes } \\
\text { ATCC } 19615\end{array}$ & $\begin{array}{l}\text { Streptococcus } \\
\text { pneumoniae } \\
\text { (clinic) }\end{array}$ & $\begin{array}{c}\text { Escherichia coli } \\
\text { ATCC } 25922\end{array}$ & $\begin{array}{l}\text { Escherichia coli } \\
\text { (clinic) }\end{array}$ \\
\hline Rossmarinus officinalis L. & $8.33 \pm 0.33^{\mathrm{f}}$ & $12.00 \pm 0.30^{\mathrm{d}}$ & $7.83 \pm 0.44^{\mathrm{f}}$ & $8.33 \pm 0.33^{\mathrm{c}}$ & $8.00 \pm 0.33^{\mathrm{c}}$ & $8.50 \pm 0.29^{\mathrm{d}}$ & $8.00 \pm 0.10^{\mathrm{d}}$ \\
\hline Menta piperita L. & $12.00 \pm 0.10^{\mathrm{d}}$ & $10.00 \pm 0.15^{\mathrm{e}}$ & $9.66 \pm 0.17^{e}$ & $10.33 \pm 0.33^{\mathrm{b}}$ & $10.17 \pm 0.17^{\mathrm{ab}}$ & $8.33 \pm 0.33^{\mathrm{d}}$ & $9.00 \pm 0.58^{\mathrm{c}}$ \\
\hline Hyssopus officinalis L. & $17.00 \pm 0.20^{\mathrm{b}}$ & $20.00 \pm 0.10^{\mathrm{a}}$ & $8.33 \pm 0.33^{\mathrm{f}}$ & $11.00 \pm 0.57^{\mathrm{a}}$ & $10.75 \pm 0.27^{\mathrm{a}}$ & $14.00 \pm 0.56^{\mathrm{c}}$ & $10.66 \pm 0.88^{\mathrm{ab}}$ \\
\hline Coriandrum sativum $\mathrm{L}$. & $11.00 \pm 0.20^{\mathrm{e}}$ & $10.00 \pm 0.10^{\mathrm{e}}$ & $15.17 \pm 0.44^{\mathrm{c}}$ & $11.00 \pm 0.58^{\mathrm{a}}$ & $11.17 \pm 0.17^{\mathrm{a}}$ & $15.50 \pm 0.29^{b}$ & $0^{\mathrm{e}}$ \\
\hline $\begin{array}{l}\text { Composition 1: Hyssopus officinalis L. } \\
+ \text { Rossmarinus officinalis L. }(1: 1)\end{array}$ & $14.16 \pm 0.17^{\mathrm{c}}$ & $19.83 \pm 0.44^{\mathrm{a}}$ & $16.83 \pm 0.44^{\mathrm{b}}$ & $10.50 \pm 0.29^{b}$ & $10.33 \pm 0.33^{\mathrm{ab}}$ & $13.83 \pm 0.44^{c}$ & $12.33 \pm 0.33^{\mathrm{a}}$ \\
\hline $\begin{array}{l}\text { Composition 2: Menta piperita L. }+ \\
\text { Hyssopus officinalis L. }(1: 1)\end{array}$ & $20.00 \pm 0.58^{\mathrm{a}}$ & $18.00 \pm 0.58^{b}$ & $10.00 \pm 0.29^{\mathrm{e}}$ & $11.83 \pm 0.44^{\mathrm{a}}$ & $10.00 \pm 0.58^{\mathrm{ab}}$ & $10.16 \pm 0.60^{\mathrm{e}}$ & $11.83 \pm 0.44^{\mathrm{a}}$ \\
\hline $\begin{array}{l}\text { Composition 3: Rossmarinus } \\
\text { officinalis L.+ Coriandrum sativum L. }\end{array}$ & $8.17 \pm 0.17^{\mathrm{f}}$ & $10.33 \pm 0.33^{\mathrm{e}}$ & $12.33 \pm 0.33^{\mathrm{d}}$ & $10.50 \pm 0.50^{b}$ & $10.50 \pm 0.50^{\mathrm{a}}$ & $13.33 \pm 0.33^{c}$ & $10.75 \pm 0.25^{\mathrm{ab}}$ \\
\hline $\begin{array}{l}\text { Composition 4: Rossmarinus } \\
\text { officinalis L. + Menta piperita L.+ } \\
\text { Hyssopus officinalis L. }\end{array}$ & $14.33 \pm 0.33^{\mathrm{c}}$ & $16.33 \pm 0.33^{\mathrm{c}}$ & $17.83 \pm 0.44^{\mathrm{a}}$ & $10.50 \pm 0.25^{\mathrm{b}}$ & $10.33 \pm 0.29^{\mathrm{ab}}$ & $18.00 \pm 0.30^{\mathrm{a}}$ & $8.25 \pm 0.25^{\mathrm{d}}$ \\
\hline
\end{tabular}

Note: data in the column followed by different letters are significantly different at $\mathrm{P}<0.05$ according to Tukey's HSD test.

Table 2

Antimycotic activity of essential oils and their compositions against typical and clinical isolates of Candida genus fungi ( $\mathrm{mm}, \mathrm{x} \pm \mathrm{SD}, \mathrm{n}=3$ )

\begin{tabular}{|c|c|c|c|c|}
\hline $\begin{array}{r}\text { Essential oils } \\
\end{array}$ & Candida albicans ATCC 885-653 & Candida albicans (clinic) & Candida tropicalis (clinic) & Candida krusei (clinic) \\
\hline Rossmarinus officinalis L. & $12.33 \pm 0.33^{\mathrm{d}}$ & $13.00 \pm 0.50^{\mathrm{d}}$ & $9.00 \pm 0.30^{\mathrm{e}}$ & $10.00 \pm 0.40^{\mathrm{e}}$ \\
\hline Menta piperita L. & $15.00 \pm 0.57^{\mathrm{b}}$ & $10.00 \pm 0.25^{\mathrm{g}}$ & $10.00 \pm 0.30^{\mathrm{d}}$ & $12.00 \pm 0.45^{\mathrm{d}}$ \\
\hline Hyssopus officinalis L & $11.50 \pm 0.20^{\mathrm{e}}$ & $12.00 \pm 0.80^{\mathrm{e}}$ & $10.00 \pm 0.20^{\mathrm{d}}$ & $15.00 \pm 0.65^{\mathrm{a}}$ \\
\hline Coriandrum sativum L. & - & - & $20.33 \pm 0.60^{\mathrm{a}}$ & $13.66 \pm 0.33^{b}$ \\
\hline $\begin{array}{l}\text { Composition 1: Hyssopus officinalis L. }+ \\
\text { Rossmarinus officinalis L. }(1: 1)\end{array}$ & $15.00 \pm 0.58^{\mathrm{b}}$ & $18.33 \pm 0.33^{\mathrm{b}}$ & $14.50 \pm 0.29^{c}$ & $12.83 \pm 0.60^{\mathrm{d}}$ \\
\hline $\begin{array}{l}\text { Composition 2: Menta piperita L. }+ \\
\text { Hyssopus officinalis L. }(1: 1)\end{array}$ & $17.80 \pm 0.33^{\mathrm{a}}$ & $16.33 \pm 0.33^{\mathrm{c}}$ & $15.00 \pm 0.58^{b}$ & $14.00 \pm 0.33^{\mathrm{b}}$ \\
\hline $\begin{array}{l}\text { Composition 3: Rossmarinus officinalis L. + } \\
\text { Coriandrum sativum L. }\end{array}$ & $11.17 \pm 0.17^{\mathrm{e}}$ & $11.17 \pm 0.33^{\mathrm{f}}$ & $15.00 \pm 0.58^{\mathrm{b}}$ & $14.00 \pm 0.50^{\mathrm{b}}$ \\
\hline $\begin{array}{l}\text { Composition 4: Rossmarinus officinalis L.+ } \\
\text { Menta piperita L. + Hyssopus officinalis L. }\end{array}$ & $13.17 \pm 0.17^{\mathrm{c}}$ & $20.33 \pm 0.33^{\mathrm{a}}$ & $14.83 \pm 0.17^{b}$ & $9.17 \pm 0.17^{\mathrm{f}}$ \\
\hline
\end{tabular}

Note: see Table 1.

The latest studies have determined the antimicrobial effect of essential oils against microorganisms of different systematic groups (Harris, 2002; Celikel \& Kavas, 2008; Sajana et al., 2013); at the same time, essential oil compositions may be of great value for the purpose of expanding the activity spectrum of antimicrobial substances. Bassole et al. (2012) noted that in essential oil compositions different terpenoid components of EOs can interact to either reduce or increase the antimicrobial efficacy. The interaction between EO compounds can produce four possible types of effects: indifferent, additive, antagonistic or synergistic effects. For instance, mixtures of cinnamaldehyde with carvacrol or thymol yielded in most cases synergistic effects against $E$. coli and $S$. typhimurium (Bassole et al., 2012). Fu et al. (2007) considered the effect of clove and rosemary essential oils taken alone and in combination. The combination was shown to have additive, synergistic or antagonistic effects against individual microorganism tests.

The experimental study (Semeniuc et al., 2017) showed antibacterial effects of several essential oils (EOs) alone and in combination against different Gram-positive and Gram-negative bacteria associated with food products: parsley, lovage, basil, and thyme EOs, as well as their mixtures $(1: 1, \mathrm{v} / \mathrm{v})$, were tested against Bacillus cereus, Staphylococcus aureus, Pseudomonas aeruginosa, Escherichia coli and Salmonella typhimurium. The studies showed that thyme EO has the highest percentage yield and antibacterial potential out of all tested formulations; its combination with parsley, lovage, and basil EOs determines a reduction of its antibacterial activity. Thereby, the studies have shown that mixtures of essential oils characterized by antimicrobial properties did not always present additive effect and increase in their antimicrobial activity. We showed the efficiency of two variants of compositions: $M$. piperita + $H$. officinalis and $H$. officinalis $+R$. officinalis. In case of mixing these essential oils, the spectrum of antimicrobial activity was expanded in comparison with their ingredients if taken separately. Determination of antimicrobial properties of essential oils compositions makes it possible to combine them in preparations applied for prevention of inflammatory processes of the the periodontium. Application of essential oils in preparations for mouth care and prevention of oral cavity infections looks promising due to their ability to inhibit the development of inflammatory processes on accountt of their antimicrobial properties.

\section{Conclusions}

Therefore, two compositions of essential oils M. piperita $+H$. officinalis and $H$. officinalis $+R$. officinalis have been experimentally proved to demonstrate a broad spectrum of antimicrobial and antimycotic activity against clinical isolates from the oral cavities of patients with 
inflammatory diseases of the periodontium, and other typical cultures of microorganisms. The obtained results provide prospects for further study of the possibilities of application of the given compositions as ingredients of preparations used for prevention of inflammatory processes of the oral cavity.

\section{References}

Assaf, A. M., Amro, B. I., Mashallah, S., \& Haddadin, R. N. (2016). Antimicrobial and anti-inflammatory potential therapy for opportunistic microorganisms. The Journal of Infection in Developing Countries, 10(5), 494.

Balouiri, M., Sadiki, M., \& Ibnsouda, S. K. (2016). Methods for in vitro evaluating antimicrobial activity: A review. Journal of Pharmaceutical Analysis, $6(2), 71-79$

Bassolé, I. H. N., \& Juliani, H. R. (2012). Essential oils in combination and their antimicrobial properties. Molecules, 17(4), 3989-4006.

Bueno, J., Demirci, F., \& Husnu Can Baser, K. (Eds.). (2017). 6: Essential oils against microbial resistance mechanisms, challenges and applications in drug discovery. Essential oils and nanotechnology for treatment of microbial diseases. Pp. 143-158.

Celikel, N., \& Kavas, G. (2008). Antimicrobial properties of some essential oils against some pathogenic microorganisms. Czech Journal of Food Sciences, 26(3), 174-181.

Fu, Y., Zu, Y., Chen, L., Shi, X., Wang, Z., Sun, S., \& Efferth, T. (2007). Antimicrobial activity of clove and rosemary essential oils alone and in combination. Phytotherapy Research, 21(10), 989-994.

Größner-Schreiber, B., Teichmann, J., Hannig, M., Dörfer, C., Wenderoth, D. F., \& Ott, S. J. (2009). Modified implant surfaces show different biofilm compositions underin vivoconditions. Clinical Oral Implants Research, 20(8), 817-826.

Harris, B. (2002). The antimicrobial properties of essential oils. International Journal of Aromatherapy, 12(2), 113.

Jakobi, M., Stumpp, S., Stiesch, M., Eberhard, J., \& Heuer, W. (2015). The periimplant and periodontal microbiota in patients with and without clinical signs of inflammation. Dentistry Journal, 3(2), $24-42$.

Kalemba, D., \& Kunicka, A. (2003). Antibacterial and antifungal properties of essential oils. Current Medicinal Chemistry, 10(10), 813-829.

Koba, K., Nénonéné, A. Y., Sanda, K., Garde, D., Millet, J., Chaumont, J.-P., \& Raynaud, C. (2011). Antibacterial activities of coleus aromaticus benth (Lamiaceae) essential oil against oral pathogens. Journal of Essential Oil Research, 23(1), 13-17.
Kryvtsova, M. V., Kohuch, T. T., Salamon, I., Spivak, M. J. (2018). Antimicrobial activity of some essential oils on Candida genus clinical isolates. Mikrobiolohichnyi Zhurnal, 80(4), 3-12.

Kryvtsova, M., Rivis, O., Babenko, L., Spivak, N., Nikolaichuk, V., Ganic, T. (2017) Antibacterial properties of essential oils against specific opportunistic pathogenic bacteria. Proceedings of 2nd Japan - Turkey International Symposium on Pharmaceutical and Biomedical Sciences (JATUSPAB-2), Trabzon. Pp. 30.

Marino, M., Bersani, C., \& Comi, G. (1999). Antimicrobial activity of the essential oils of Thymus vulgaris L. measured using a bioimpedometric method. Journal of Food Protection, 62(9), 1017-1023.

Millezi, A. F., Caixeta, D. S., Rossoni, D. F., Cardoso, M. das G., \& Piccoli, R. H. (2012). In vitro antimicrobial properties of plant essential oils Thymus vulgaris, cymbopogon citratus and laurus nobilis against five important foodborne pathogens. Food Science and Technology, 32(1), 167-172.

Mohamed, S. B., \& Eddine, A. D. (2010). Antibacterial activity of essential oils of some Algerian aromatic plants against multidrug resistant bacteria. Journal of Essential Oil Bearing Plants, 13(3), 362-370.

Murbach Teles Andrade, B. F., Nunes Barbosa, L., da Silva Probst, I., \& Fernandes Júnior, A. (2013). Antimicrobial activity of essential oils. Journal of Essential Oil Research, 26(1), $34-40$.

Newman, D. J., \& Cragg, G. M. (2007). Natural products as sources of new drugs over the last 25 years. Journal of Natural Products, 70(3), 461-477.

Rhos, J. L., \& Recio, M. C. (2005). Medicinal plants and antimicrobial activity. Journal of Ethnopharmacology, 10(1-2), 80-84.

Salamon, I., Ibraliu, A., \& Kryvtsova, M. (2017). Essential oil of common juniper (Jiniperus communis L.) in Albania. Scientific Bulletin of the Uzhhorod University, Series Biology, 42, 72-75.

Schindel, L. (2013). Antibiotic-resistant bacteria. Unexpected Reactions to Modern Therapeutics, 94-101.

Semeniuc, C. A., Pop, C. R., \& Rotar, A. M. (2017). Antibacterial activity and interactions of plant essential oil combinations against Gram-positive and Gram-negative bacteria. Journal of Food and Drug Analysis, 25(2), 403-408.

Sujana, P., Sridhar, T. M., Josthna, P., \& Naidu, C. V. (2013). Antibacterial activity and phytochemical analysis of Mentha piperita L. (Pepper mint) - an important multipurpose medicinal plant. American Journal of Plant Sciences, 4(1), 77-83.

Tada, A., Senpuku, H., Motozawa, Y., Yoshihara, A., Hanada, N., \& Tanzawa, H. (2006). Association between commensal bacteria and opportunistic pathogens in the dental plaque of elderly individuals. Clinical Microbiology and Infection, 12(8), 776-781. 